\title{
Electronic marketing and the new anti-spam regulations
}

Received: 15th January, 2004

\section{Ewan Nettleton}

is a solicitor in the intellectual property department at Bristows. He specialises in intellectual property law. He has an MA in chemistry and a DPhil in protein chemistry.

\begin{abstract}
Spamming is a global problem which affects almost everyone who uses e-mail, text messages or other means of electronic communication. Estimates suggest that the quantity of junk e-mail has increased by as much as 300 per cent since 1999, and that spam now accounts for over half of all e-mail traffic. In the face of this global problem, the European Commission recently adopted a revised Directive dealing with unsolicited electronic communications. This has now been implemented by legislation in a number of EU member states, including the UK.

Unfortunately, the new laws may do little to prevent spam as the vast majority of it originates in Asia and the USA. Nevertheless, it is important for UK and European businesses to acquaint themselves with the new rules and to seek to ensure that their marketing practices are compliant, so as to distinguish themselves from the spammers. This paper sets out the new legal requirements which relate to electronic communications in general terms and makes practical suggestions on how to comply. It also briefly considers the new rules from a global perspective.
\end{abstract}

\section{INTRODUCTION TO THE NEW REGULATIONS}

The Directive on Privacy and Electronic Communications (2002/58/EC) (the

'Directive') was to be adopted by each EU member state by 31st October, 2003; the UK was one of only six countries to provide the Commission with details of its implementing legislation in time. The new UK law (the Regulations) ${ }^{1}$ came into effect on 11th December, 2003 and supplements the UK's current data protection legislation. Whilst being 'technology neutral', the Regulations

Ewan Nettleton Bristows, 3 Lincoln's Inn Fields, London WC2A 3AA, UK.

Tel: +44 (0)20 74008000 ; e-mail: ewan.nettleton@ bristows.com cover, amongst other things, direct marketing by phone, fax and electronic communications; subscriber directories; internet cookies; and value added services which rely on traffic or location data.
The Regulations will be enforced by the Information Commissioner, who has released Guidance notes ${ }^{2}$ on their interpretation.

\section{APPLICATION OF THE REGULATIONS TO MARKETING BY ELECTRONIC MAIL}

\section{Scope of the Regulations}

The key regulations applying to electronic mail apply to communications sent for the purpose of 'direct marketing. ${ }^{3}$ This term is defined as,

'the communication (by whatever means) of any advertising or marketing material which is directed to particular individuals'. 
It therefore covers a wide range of subject matter, including, for example, appeals made by charities and political parties for funds or support, or those designed to encourage individuals to write to their Member of Parliament or attend public rallies or meetings. ${ }^{5}$

The Regulations seek to be 'technology neutral', and cover a wide range of electronic mail including text, picture and video messages as well as e-mail. The Guidance makes clear that even voicemail and answerphone messages left by marketers making calls that would otherwise be 'live' fall within the definition. ${ }^{6}$ Fax communications, on the other hand, are covered separately in the Regulations (and not, therefore, discussed further here).

\section{Requirements for compliance}

Two general requirements apply to all electronic mail sent for the purpose of direct marketing: ${ }^{7}$

(i) The mail must not disguise or conceal the identity of its sender or the person on whose behalf it was sent; and

(ii) A valid address must be provided for the recipient to opt-out of receiving further communications.

Hence, electronic marketing mails should always identify the sender and provide an opt-out address, even where they are of limited length (eg mobile phone texts). The address must be valid and the Guidance makes clear that whilst e-mail addresses in the online environment suffice, telephone numbers (even freephone numbers) do not.

The remaining requirements of the Regulations pertinent to electronic mail only apply to unsolicited communications sent to individual subscribers. To be solicited (rather than unsolicited), a message must have been actively invited by the recipient, eg where you are contacted by someone who requests marketing information on your products. The definition of 'individuals' (as distinct from 'corporate subscribers') in the Regulations covers any living individual. It also includes many unincorporated bodies of such individuals and is therefore somewhat problematic as explained below.

Unsolicited communications can only be sent to individual subscribers where either:

(i) The individual has notified the sender that they consent for the time being to receiving such communications (ie has 'opted in'); or

(ii) Circumstances are such that there has been a 'soft opt-in'.

To opt in, the individual must have actually given their consent to receiving the marketing communications. The 'consent' of a data subject is defined in the Directive as follows: 'any freely given specific and informed indication of his wishes by which the data subject signifies his agreement'. This definition is referred to in the Guidance, which points out that consenting does not simply nor necessarily mean ticking a box — the individual should understand what they are consenting to. Individuals can consent by a whole variety of methods, including clicking on an icon, sending an e-mail, subscribing to a service or ticking a box, so long as they understand the effect of doing so. Furthermore, consent must be positive; it is not necessarily sufficient for the individual merely to have omitted to opt out of receiving such communications (eg by not ticking the marketer's traditional 'opt-out' box). ${ }^{8}$

If they have not consented in the 
manner set out above, marketing to an individual using electronic mail will only be possible if the following circumstances, which lead to a 'soft opt-in' arise:

(i) The recipient's details were obtained in the course of the sale or negotiations for the sale of a product or a service to the recipient;

(ii) The marketing material being sent concerns similar products or services; and

(iii) The recipient (a) was given a simple means (which was free save for the cost of transmission) of refusing the use of his contact details for marketing purposes at the time when they were collected and at the time of each subsequent communication to him and (b) he has not refused the use of his details.

The Guidance points out that a sale does not have to have been completed for the soft opt-in to apply. Hence, where an individual has actively expressed an interest in purchasing a product or service or similar products or services at the time when they provided their details, they may be sent electronic marketing mail unless and until such time as they opt out of receiving it. It should be noted, however, that express communication of the individual's interest is required. For example, the use of cookie technology to identify areas of interest whilst potential customers are browsing a website would not suffice. Likewise, requests for information which do not concern a particular product or service, eg information about branches in the area or about the business, would not constitute a soft opt-in. Furthermore, where unsolicited mail is sent in response to a soft opt-in, recipients must be given a means of objecting that is free, save for the cost of transmission, each time (as opposed to simply providing a valid address for doing so).

\section{Some key terms}

A number of terms that are used in the Regulations warrant further explanation. First, consent to opt in to receiving unsolicited marketing communications is expressed as being given 'for the time being'. This term is not specifically defined in the Regulations, but it implies that the consent has a transient nature and the Guidance makes clear that consent does not lapse after any specific period of time. ${ }^{9}$ Rather, the consent will remain valid until there is a good reason why it should not, eg where it has been specifically withdrawn or it is otherwise clear that the recipient no longer wishes to receive marketing communications.

The Guidance also suggests that opt-outs will likewise apply for the time being, so that they only lapse when there is a good reason for the objection to be ignored, eg because the recipient has indicated that they now consent to receiving such communications.

Another significant term is 'similar products and services', which relates to soft opt-ins. Not only must there have been some product or service offered at the negotiations where the individual's contact details were obtained, but it must be similar to those offered in the marketing communication. The Guidance explains that the test is one of the individual's 'reasonable expectation'; ${ }^{10}$ ie would they reasonably expect to receive marketing materials about the products or services described having previously been in contact about another product or service. An example is given of an online supermarket shopper who would reasonably expect to receive promotional e-mails relating to the range of goods available at the supermarket. The Guidance points out that individuals 
should in any case be given the opportunity of opting out if they feel that a marketer is stretching the boundaries, and emphasises that particular attention will be paid to failures to comply with opt-out requests.

\section{Potential problem areas}

The new rules raise a number of problem areas, such as the distinction under the Regulations between individual and corporate subscribers and how organisations may use marketing lists. The individual/corporate distinction is important because consent must be obtained from individuals before unsolicited marketing communications can be sent to them (unless circumstances for a soft opt-in arise). The definition of 'individuals' covers sole traders, such as consultants who carry on their businesses in their own names rather than under the umbrella of a company, and partnerships (such as the vast majority of solicitors', accountants' and architects' firms) based in England, Northern Ireland and Wales. Other organisations, principally UK companies, limited liability and Scottish partnerships and governmental organisations (including hospitals and other public bodies), fall within the definition of 'corporate subscribers' and so may be sent unsolicited marketing mail without prior consent, as long as the requirements of the Data Protection Act 1998 are met. Marketing materials that are clearly aimed at individuals within 'corporate' organisations (eg invitations to purchase Viagra sent to individuals within a shipping company at their corporate e-mail addresses) are nevertheless treated as being sent to corporate subscribers in the Regulations. ${ }^{11}$

Marketers, therefore, need to be able to recognise which category potential recipients fall into and ensure that they comply with the appropriate rules when marketing to individuals. This makes life difficult, because it is not always obvious from an e-mail address or business card whether a particular organisation is a partnership, limited liability partnership or company; the author's e-mail address (ewan.nettleton@bristows.com) taken alone, for example, is if anything indicative of a corporate organisation. When marketing to partnership subscribers, the question also arises as to whose consent must be obtained. The Guidance notes state that, strictly speaking, the consent of the individual recipients or persons (such as their secretaries) who can reasonably be regarded as consenting for them should be obtained. However, the Information Commissioner recognises that there are circumstances where the wishes of the partnership organisation to receive marketing materials should override the wishes of individual employees. Hence, marketers may obtain consent from a single person (such as the managing partner) for the partnership as a whole to receive such materials if it is reasonable to assume that the person in question has the authority to give such consent. The consent of other individuals in the partnership should not, however, be treated as consent of all its individuals and, as with any information about an individual, marketers should ensure that they comply with the principles of the Data Protection Act 1998, even if consent on behalf of the partnership has been obtained.

Application of the Regulations to marketing lists also creates some difficulties, and, like the distinctions between individuals and corporate subscribers, these are discussed in some detail in the Guidance notes. ${ }^{12}$ Use of marketing lists compiled before 11th December, 2003, in accordance with the legislation in force at the time is permitted so long as the lists have 
been used recently and the intended recipients have not opted out.

However, the opt-out requirements depend on how the list was compiled. If it was compiled on a clear prior consent basis, the only requirement is that a valid address for opting out be provided. If not, an opt-out opportunity must be provided with every message sent (in an analogous manner to unsolicited mail sent in response to a soft opt-in).

Where marketing lists have been obtained from a third-party broker, under the Regulations it is still the responsibility of the marketer to ensure that the rules have been complied with. Notably, the Information Commissioner has indicated that whilst some latitude may be exercised in relation to lists compiled legitimately before 11 th December, 2003, it is difficult to see how third-party lists could be compiled and used legitimately after that date unless the individual subscribers in the list have expressly invited (ie solicited) marketing by electronic mail. ${ }^{13}$ The use of particular types of lists in various circumstances is discussed in more detail in the Guidance notes.

\section{PRACTICAL SUGGESTIONS FOR COMPLIANCE}

In order to check and help to ensure compliance, those engaging in marketing by electronic mail may wish to:

- Review the information in existing marketing lists against the Regulations and Guidance and seek legal advice and/or assurances from third-party providers as required.

- Ensure that contacts in marketing lists are classified as either individual or corporate subscribers, and whether the lists record whether they have invited, consented to or opted out of the receipt of marketing materials.

- Make the opt-out and opt-in records in marketing databases media specific, eg e-mail, telephone calls, etc (because there are different rules for different types of communications).

- Put in place procedures for ensuring that electronic marketing mails are sent only in accordance with the Regulations and Guidance.

- Review the wording of all data protection and privacy statements in light of the new requirements.

- Train the employees who compile and use the marketing databases.

- Carry out regular checks to verify the quality of data and ensure that all the appropriate details are being included.

It should be noted that those who engage in pan-European marketing from the UK need to comply with the Regulations when sending or instigating the sending of electronic mail elsewhere in the EU. They should also be aware that whilst the provisions of the Directive should ultimately be implemented throughout the EU, each member state was given the option of extending the provisions relating to individuals to cover corporate subscribers, and that more stringent regimes may be in place. Italy, for instance, has much tougher anti-spam legislation than the UK and has made spamming a criminal offence. Hence legal advice on implementation in other jurisdictions may be required.

\section{THE GLOBAL PERSPECTIVE}

As noted above, the vast majority of spam originates from the USA and Asia, and hence the implementation of the Directive is likely to do little to cut down its volume. In December 2003, the USA enacted federal legislation seeking to curb the stream of unsolicited 
e-mails and further US bills are in the pipeline. ${ }^{14}$ A number of US states have also put in place their own anti-spam legislation. ${ }^{15}$ However, the USA has generally taken the approach that individuals need to opt out rather than opt in to receiving marketing e-mails, so it is likely, for the time being at least, that the most persistent spammers will remain undeterred. Indeed, as a recent European Commission paper suggests, ${ }^{16}$ there probably is no silver bullet for preventing spam, and to be reduced effectively it will need to be dealt with on many fronts.

\section{CONCLUSIONS}

The UK Regulations have put in place new rules relating to privacy and electronic communications which, whilst they may not curb the quantities of spam, have far reaching consequences for the way legitimate businesses carry out marketing by electronic means. Where marketing is carried out using electronic mail, the requirements necessitate the use of appropriate systems to classify potential recipients in marketing lists and to record information such as consents and objections to receiving marketing materials. Such information must then be put to use by marketers when targeting potential customers.

\section{(C) Bristows}

\section{References and notes}

1 The Privacy and Electronic Communications (EC Directive) Regulations 2003.

2 Guidance to the Privacy and Electronic Communications (EC Directive) Regulations 2003, which is available on the Information Commissioner's website (http://www.informationcommissioner.gov.uk).

3 Regulations 22 and 23.

4 Section 11 of the Data Protection Act 1998.

5 This specific example is given in the Guidance (Part 1, p. 3).

6 Part 1, p. 20 of the Guidance.

7 Regulation 23.

8 Although the Guidance suggests that a suitably prominent opt-out box may assist in establishing that consent was given (Part 1, p. 5).

9 See Part 1, p. 5 of the Guidance.

10 Part 1, p. 22.

11 Although, as the Guidance notes (Part 1, p. 29), such promotional materials may be covered in the Data Protection Act 1998.

12 See Part 1, pp. 24-26 (mailing lists) and 28-31 (corporate/individual subscribers).

13 This is because consent to unsolicited mail must have been previously notified to the sender under the regulations in circumstances where a soft opt-in does not apply.

14 The final version of the Controlling the Assault of Non-Solicited Pornography and Marketing Act (the 'CAN-SPAM Act') was approved by the Senate in November 2003, and by the House of Representatives in December 2003. It was signed by President Bush on 16th December, 2003 and came into effect on 1st January, 2004. The CAN-SPAM Act, amongst other things, places various requirements on unsolicited commercial e-mail messages and prohibits the use of misleading subject lines and headers in such messages.

15 For example, the recent new legislation in California. See www.spamlaws.com; www.spamlaws.com/state/ca1.html for further information on California spam legislation.

16 Entitled 'Combating spam on all fronts', available through www.europa.eu.int. 